\title{
Внешняя политика Российской Федерации начала XXI вв. в контексте теории «Вызова и Ответа» А.Дж. Тойнби
}

\author{
Вафин М.O. \\ Дальневосточный юридический институт МВД России, \\ Россия, 680020, Хабаровский край, г. Хабаровск, пер. Казарменный, д. 15 \\ E-mail: vafin_1992@mail.ru
}

\begin{abstract}
Аннотация. В данной статье представлен анализ современного геополитического положения Российской Федерации через призму теории «Вызова и Ответа» А.Дж. Тойнби. Раскрыто содержание таких категорий, как «вызов», «ответ», «творческое меньшинство» с приведением конкретных исторических примеров. Ключевыми «вызовами» России в настоящее время являются внешнеполитические, детерминируемые геополитическими амбициями и гегемонистическими взглядами стран Запада во главе с США. В статье освещены основные направления формирования внешнеполитических «вызовов», а также «ответы», которые дает на них Россия. По мнению автора, «ответы», формируемые Российской Федерацией, в настоящее время являются верными, достойными, демонстрирующими свою состоятельность, коррелируемые с теорией А.Дж. Тойнби, способные обеспечить дальнейшее существование русской цивилизации.
\end{abstract}

Ключевые слова: «вызов», «ответ», «творческое меньшинство», геополитика, США, Российская Федерация, русская цивилизация.

Для цитирования: Вафин М.О. 2021. Внешняя политика Российской Федерации начала XXI вв. в контексте теории «Вызова и Ответа» А.Дж. Тойнби. Via in tempore. История. Политология, 48 (2): 477-485. DOI: 10.52575/2687-0967-2021-48-2-477-485.

\section{Foreign policy of the Russian Federation beginning XXI century in the context of the theory of "Challenge-and-Response» by A.J. Toynbee}

\author{
Maxim O. Vafin \\ Far Eastern Home Ministry Law Institute of Russia, \\ Russia, 680020, Khabarovsk Krai, Khabarovsk, Kazarmenny lane, 15 \\ E-mail: vafin_1992@mail.ru
}

\begin{abstract}
Abstract. This article presents an analysis of the current geopolitical situation of the Russian Federation through the prism of the theory of «Challenge-and-Response» by A.J. Toynbee. This theory is one of the key ones in the philosophy of history, since it is aimed at substantiating the civilizational approach to the historical process. The article reveals the content of the categories «challenge», «response» and «creative minority». Specific historical examples are provided to detail these definitions. Currently, the key «challenge» for Russia is such situations that are determined by foreign policy conditions, due to the geopolitical ambitions and hegemonic views of Western countries, led by the United States. The USA is trying to take a leading position in world politics, and therefore it is trying to promote its interests anywhere in the world where it sees an opportunity to achieve them. The article highlights the main directions in which foreign policy «challenge» are formed, as well as the «response» to them that Russia gives. According to the author, the «response» formed by the Russian Federation are currently correct, worthy, demonstrating right to exist, correlated with the theory of A.J. Toynbee and able to ensure the continued existence of Russian civilization.
\end{abstract}

Keywords: «challenge», «response», «creative minority», geopolitics, USA, Russian Federation, Russian civilization. 
For citation: Vafin M.O. 2021. Foreign policy of the Russian Federation beginning XXI century in the context of the theory of «Challenge-and-Response» by A.J. Toynbee. Via in tempore. History and political science, 48 (2): 477-485 (in Russian). DOI: 10.52575/2687-0967-2021-48-2-477-485.

В настоящее время с геометрической прогрессией вновь происходит накал международной обстановки. Одними из самых значимых субъектов такого противостояния являются Россия и США. Политическое руководство последних еще с середины XX века сформировало внешнеполитическую доктрину, направленную на получение гегемонии и установление однополярного мира в планетарных масштабах. Ключевым препятствием и главным противником реализации данных целей в XX веке являлся СССР.

Наступление XXI века не изменило приоритеты внешней политики США - в настоящее время они по-прежнему всевозможными методами и способами пытаются вмешиваться в политические процессы, происходящие в любой точке планеты. Однако достигнуть мирового господства США не может, поскольку им препятствует полноправный наследник СССР - Российская Федерация. Обозначенную тенденцию мы можем увидеть в концепции «Вызова и Ответа», сформулированной А.Дж. Тойнби во второй половине XX века.

А.Дж. Тойнби является одной из ключевых фигур в философии истории, который окончательно сформулировал цивилизационный подход к историческому процессу. Важное место в теории британского профессора занимает вопрос о механизме возникновения цивилизаций. Английские ученые утверждают, что цивилизации самостоятельно возникнуть не могут, для этого необходимы определенные условия, получившие у него название ситуации «Вызова и Ответа». При этом данная ситуация у А.Дж. Тойнби обличена в форму теории, действие которой было описано в книге «Постижение истории»[Тойнби, 2004]. Так, трансформация общества из примитивного состояния в цивилизацию начинается с того момента, когда возникают определенные обстоятельства («вызов»), ставящие под угрозу само существование данного общества. Однако процессы роста цивилизации будут запущены в том случае, если общество сможет дать адекватный и верный «ответ» на возникший «вызов». Помимо этого, для одних обществ определенные «вызовы» будут выступать толчком для становления и развития цивилизации, тогда как в других обществах аналогичные «вызовы» не приведут к наступлению подобных результатов. Например, не все народы древности, которые проживали в Иорданской долине, долине Нила, в районе Рио-Гранде и междуречья Тигра и Евфрата, находясь в сходных климатических условиях, при наличии полноводных рек со среднегодовой плюсовой температурой 21 градус, пришли к одинаковым результатам. Из перечисленных географических ареалов расселения народов древности цивилизации возникли лишь в долине Нила (Египетская) и в междуречье Тигра и Евфрата (Шумерская) [Тойнби, 2003, с. 271]. Другим примером является возникновение цивилизации в высокогорном плато в Андах и не наступление аналогичных результатов в высокогорье Кении. Возникает закономерный вопрос о причинах кардинально различных результатов.

Для ответа на поставленный вопрос А.Дж. Тойнби приводил следующий аргумент. Ключевое условие возникновения цивилизаций базируется на способности общества выйти за пределы рамок обычаев, традиций, преодолеть социальную инерцию и дать адекватный «ответ». При этом важная роль в формировании такого «ответа» отводится не всему обществу в целом, поскольку оно не способно самостоятельно сформировать достойный «ответ», а определенной его части - конкретным индивидам, группам лиц, творцамодиночкам или «творческому меньшинству» [Чепиков, 2013, с. 59], обладающему способностью к творчеству, созданию чего-то нового. Подобная категория людей способна отреагировать на «вызов», преодолевая закостенелую консервативность общества. По мнению А. Тойнби, такими творцами истории могут стать личности духовно одаренные, достигшие высшего уровня индивидуальности, способные дать отпор внешнему давлению, гото- 
вые к трансформированию окружающей их действительности, обладающие характеристиками, способствующими распространению своего влияния на других. Стоит подчеркнуть, что наличие инновационных воззрений, стремлений, способностей у людей британский философ рассматривает в качестве творческой мутации. Наличие подобных мутаций во внутреннем мире человека приводит к изменению во всем обществе, что выступает одним из ключевых факторов становления и развития цивилизации.

Однако сам факт наличия творческого меньшинства не детерминирует возникновение цивилизации. Они способны сформулировать «ответ», но не способны реализовать его самостоятельно. Для формирования достойного «ответа» данная категория людей должна увлечь за собой пассивное большинство. Большим значением здесь обладает социальное подражание, в результате которого решения, сформированные «творческим меньшинством», становятся достоянием «нетворческого большинства». Поскольку «ответ» будет адекватным в том случае, если на него реагирует все общество. Однако, как утверждает А.Дж. Тойнби, процесс этот крайне болезненный [Тойнби, 1991, с. 261], поскольку может затронуть отрыв общества от фундаментальных традиций, установок и ценностей. Например, формируя адекватный «ответ», вызванный внешнеполитическим «вызовом» технологического и военного отставания России от европейских стран, а также назревавшей на горизонте войной со Швецией, Пётр I, как представитель «творческого меньшинства», пришел к необходимости внедрения инноваций, которые силой насаждались во всех сферах жизни общества и для всех слоев населения, за что будущий император получил от старообрядцев прозвище «Антихрист». Но если творцы-одиночки достигают успеха в преодолении инерции традиций, враждебности окружения и провоцируют социальное подражание, то это приводит к установлению в данном обществе нового порядка, становлению и развитию цивилизации.

На наш взгляд, несмотря на критику теоретических положений А.Дж. Тойнби, его работа внесла вклад в формирование подхода к историческому процессу, сформулировав историческую закономерность, примеры проявления которой демонстрируются в современном геополитическом положении России. В настоящей работе важно отметить то, насколько применяемые способы решения возникших проблем являются адекватными и верными, подпадающими под категорию «ответа».

Объём работы не позволяет раскрыть все современные «вызовы», стоящие перед Российской Федерацией. В связи с чем рассмотрим наиболее актуальный «вызов», детерминированный внешнеполитической обстановкой и геополитическим положением России.

Исторически сложилось, что перед русской цивилизацией всегда были «вызовы», которые в одном случае могли привести к упадку государства, потери его независимости, в другом - к трансформации в категорию «недоразвившейся» цивилизации (как утверждал А.Дж. Тойнби). Россия на всем своем историческом пути развития часто демонстрировала правильные «ответы» на возникающие «вызовы». Так, исходя из анализа Отечественной истории, можно обозначить следующие события, выступающие примером реализации концепции «Вызов и Ответ»: вторжение ливонских рыцарей на территории русских княжеств было остановлено войсками князя Александра Невского 5 апреля 1242 г. в битве на Чудском озере; Смутное время начала XVII века, в условиях которого русское государство было на грани уничтожения, было спасено собственным народом, сплотившимся вокруг лидеров Второго народного ополчения Кузьмы Минина и Дмитрия Пожарского в 1612 г. Второе народное ополчение выбило польские войска из Москвы, в результате чего Русская цивилизация была спасена от катастрофы; угроза потери независимости Российской империи в ходе Наполеоновского нашествия 1812 г. была устранена стратегическипродуманными действиями русской армии под командованием М.И. Кутузова. Как видим, на протяжении всего исторического развития Российское государство не раз демонстрировало достойные, адекватные «ответы» на внешнеполитические «вызовы». В схожих условиях находится и современная Россия. Так, А.Дж. Тойнби считал, что российское 
государство стоит на распутье между вступлением и получением достойного места в западном мире и сохранением текущих позиций обособленно от запада, с перспективой построения собственного «антизападного контрмира» [Иванова, 2015, с. 25].

Проблема выбора для Российской Федерации действительно является внешнеполитической и в тоже время экзистенциальной проблемой. Однако наряду с этим продолжает сохранять свою актуальность проблема противостояния востока и запада, России и США, что находит свое отражение в том числе в обострении геополитической обстановки на территориях приграничных к первой стране. Так, из-за недавних событий на Украине Россия была подвергнута частичной политической и экономической блокаде.

Некоторые исследователи даже отмечают возобновление новых витков «холодной войны» или наступление «второй холодной войны» между Россией и США с их союзниками [Иванова, 2015, с. 25]. Совокупность фактов подтверждает данное утверждение. Так, основные базы НАТО (магистральные направления деятельности которого, её характер и интенсивность определяют США), базы самих Соединенных Штатов расположены в странах Европы, в том числе Восточной. Это обеспечивает полный контроль со стороны США над данными государствами. Важно подчеркнуть, что в орбиту влияния Североатлантического альянса попадает все большее количество стран. Так, в 1999 году в рамках четвертого расширения в НАТО вступили бывшие страны социалистического блока - Польша, Венгрия и Чехия [NATO, 2020]. В 2004 году НАТО приблизилось вплотную к границам России за счет вступления в данную организацию в рамках пятого расширения стран Прибалтики - Латвия, Литва, Эстония. Кроме того, в НАТО в 2004 году вошли и другие страны Восточной Европы - Болгария, Румыния, Словакия, Словения, Черногория [Тойнби, 1991, с. 261]. В марте 2020 года прошло «восьмое расширение НАТО» - в состав альянса вступила Северная Македония ${ }^{120}$.

Другим примером управления социально-политическими процессами со стороны США в Восточной Европе является организованный и проведенный при их пособничестве государственный переворот на Украине - Евромайдан 2013-2014 года. В его результате к власти пришла прозападная националистически настроенная политическая элита [Глазьев, 2016].

Страны Запада по распространению своего влияния не ограничиваются европейским направлением. США и их союзниками была нанесена серия «ударов» в период «Арабской весны» 2011 года по ближневосточным государствам в форме организации и поддержки «цветных революций». Соединенные Штаты Америки также являются инициаторами гражданской войны в Сирии, которая началась в 2011 году ${ }^{121}$. Деятельность США в данном государстве сводилась к попытке установить марионеточное правительство при прямой поддержке вооруженной, «демократической» оппозиции террористического толка [Блиндер Е., 2020].

В Средней Азии США пытаются получить контроль над Афганистаном, что вызвано не только возможностью ведения государственного наркобизнеса и параллельной травли населения стран - геополитических конкурентов США. Афганистан рассматривается Соединенными Штатами Америки как плацдарм для дальнейшей деятельности террористических ячеек, действовавших в Сирии, откуда они были выбиты в ходе военного вмешательства России. Цель экспансии террористов будет лежать на севере, и это - территория Российской Федерации. По мнению экспертов, Афганистан выгоден для потенциального продвижения экстремистов к границам России через Туркменистан, богатый запасами газа [Делягин, 2016].

${ }^{120}$ North Macedonia joins NATO as 30th Ally. 2020. Official website of the North Atlantic Treaty Organization. URL: www.nato.int/cps/en/natohq/news_174589.htm?selectedLocale=en (accessed: 08 April 2021).

${ }^{121}$ США готовили гражданскую войну в Сирии задолго до ее начала. 2017. Сетевое издание «Военное обозрение». URL: https://topwar.ru/23563-ssha-gotovili-grazhdanskuyu-voynu-v-sirii-zadolgo-do-eenachala.html (дата обращения: 05.04.2021). 
В Азиатско-Тихоокеанском регионе для обеспечения контроля над береговой зоной Евразии, противодействия в первую очередь России, США разместили свои военные базы в Японии, Южной Корее. Кроме того, Соединенные Штаты Америки планируют разместить на территории данной страны и свои стратегические силы ${ }^{122}$.

Помимо этого, США стремятся к установлению контроля над Арктикой и Северным Ледовитым океаном. Арктика представляет собой политический интерес для всего мирового сообщества не только с точки зрения экономики (присутствуют запасы нефти, газа), но и с точки зрения территориальных притязаний и реализации геополитических амбиций в данном регионе. Так, в Арктике Соединенные Штаты Америки намерены развернуть системы ПРО, а также свои военно-морские силы. По заявлениям руководителей НАТО, данные процессы будут ускоряться по мере таянья льдов Северного Ледовитого океана ${ }^{123}$.

Добавим, что США - одна из стран в мире, флот которой дислоцируется за пределами береговых границ морской акватории ${ }^{124}$. Военно-морские силы, расположенные за пределами береговых линий США, свидетельствует о преобладании «хищнической» парадигмы ведения внешней политики, что также создает ситуацию «вызова». Российская Федерация в своем распоряжении имеет четыре оперативно-стратегических и одно оперативное объединение Военно-Морских сил: Северный флот, Балтийский флот, Черноморский флот, Тихоокеанский флот, Каспийская морская флотилия соответственно. При этом дислокации флотов сформированы таким образом, чтобы непосредственно обеспечивать безопасность береговых границ Российского государства. Однако и у России есть военноморские соединения, расположенные за пределами береговых границ морской акватории в Сирии, что является гораздо меньшим масштабом, чем у США.

Примерами внешнеполитических «вызовов» правового характера, исходящих со стороны западного мира, являются следующие события. Конгрессом США 4 декабря 2014 г. была принята резолюция № 758, содержание которой носило критический и осуждающий характер относительно действий Российской Федерации ${ }^{125}$.

Выше обозначенные положения, связанные с внешнеполитической деятельностью США и их союзников, справедливо можно рассматривать как реальные «вызовы», стоящие перед Российской Федерацией, полностью укладываемые в теорию «Вызов и Ответ» А.Дж. Тойнби.

Перед рассмотрением «ответов», которые дает русская цивилизация на «вызовы» Запада, важно отметить, что внешняя политика России направлена на выстраивание отношений сотрудничества, диалога и гармоничного многополярного мироустройства. Однако посягательства извне, направленные на конституционные основы государства, в рамках самозащиты подлежат ликвидации посредством применения силы. Так, Президент Российской Федерации В.В. Путин подчеркнул, что для устойчивого и долгосрочного развития общества необходима мирная политическая обстановка. Помимо этого, глава государства отметил: «...вся работа по повышению обороноспособности имеет только одну цель, она направлена на обеспечение безопасности страны и наших граждан, чтобы никто

122 Зачем США хотят разместить стратегические силы в Южной Корее. 2017. Новостной интернет портал «RT на русском». URL: https://yandex.ru/turbo?text=https://russian.rt.com/world/article/444026strategicheskoe-orugie-ssha\&fallback=1 (дата обращения: 02.04.2021).

${ }^{123}$ Геостратегия «Анаконда» и Евразия. 2016. Информационно-аналитический портал «Геополитика». URL: https://www.geopolitica.ru/article/geostrategiya-anakonda-i-evraziya (дата обращения: 08.04.2021).

${ }^{124}$ ВМФ США: история, структура и состав. 2019. Сетевое издание «Военный обзор». URL: https://militaryarms.ru/armii-mira/vmf-usa/\#h2_2 (дата обращения: 01.05.2021).

${ }^{125}$ H. Res.758 - Strongly condemning the actions of the Russian Federation, under President Vladimir Putin, which has carried out a policy of aggression against neighboring countries aimed at political and economic domination. 2014. Congress.gov is the official website for U.S. federal legislative information. URL: https://www.congress.gov/bill/113th-congress/house-resolution/758/text (accessed: 28 March 2021). 
не только не мог помыслить об агрессии против России, но даже о том, чтобы попытаться использовать методы силового давления в отношении нашей страны». В завершении В.В. Путин заявил следующее: «Перед нами стоят масштабные задачи. Мы идём к их решению системно и последовательно, выстраивая такую модель социального, экономического развития, которая позволит обеспечить наилучшие условия для самореализации человека, а значит, дать достойные ответы на вызовы стремительно меняющегося мира, сохранить Россию как цивилизацию, основанную на собственной идентичности, на многовековых традициях, на культуре наших народов, ценностях и наших традициях» ${ }^{126}$.

На возникшие «вызовы», детерминированные внешнеполитической обстановкой, русская цивилизация дает следующие «ответы». 25 декабря 2014 г. Президентом России была утверждена новая Военная доктрина Российской Федерации ${ }^{127}$ (далее - Доктрина), в пункте 27 которой закреплено следующее положение: «Российская Федерация оставляет за собой право применить ядерное оружие в ответ на применение против нее и (или) ее союзников ядерного и других видов оружия массового поражения, а также в случае агрессии против Российской Федерации с применением обычного оружия, когда под угрозу поставлено само существование государства». Данным актом акцентируется внимание на новых внешнеполитических угрозах, детерминируемых в том числе дестабилизированной обстановкой на юго-востоке Украины. Доктриной впервые в российском военном законодательстве признается в качестве одного из видов внешних угроз информационный подрыв исторических, духовных и патриотических традиций в сфере государственной защиты.

Помимо формирования «ответов» на законодательном уровне, Россия ведет активную внешнюю политику, направленную на выстраивание отношений равноправного партнерства и мирного конструктивного сосуществования со странами ближнего и дальнего зарубежья. Например, в рамках международной организации БРИКС с такими государствами, как Бразилия, Индия, Китай, ЮАР, выстраивание сотрудничества в рамках ШОС, Таможенного союза ЕАЭС с Беларусью, Казахстаном, Арменией и Киргизией.

Помимо этого, Россия усиливает сотрудничество с Турцией, которая во внешней политике переориентировалась со стран запада на восток. Так, в 2020 г. Россия и Турция заключили уже второй контракт на поставку последним второго полка систем ПВО С$400{ }^{128}$. Наряду с этим Россия активно развивает военно-технический потенциал, совершенствуя сухопутные, морские и воздушные силы ${ }^{129}$. По утверждениям западных СМИ, Россия активно развивает те отрасли военной промышленности и техники, в которых до сих пор лидером считалась США и с которыми последним будет сложно конкурировать ${ }^{130}$.

На территориях Ближнего Востока Россия также укрепляет свои позиции. Так, с началом военной поддержки легального Сирийского правительства российскими войсками первые одержали победу над оппозиционными силами. Данное событие в конечном итоге привело к окончанию крупномасштабных боевых действий в Сирии. Так, министр иностранных дел С.В. Лавров отметил: «Военное противостояние между правительством страны и оппозицией закончилось. Есть только две горячие точки. Первая - Идлиб, территория которого контролируется группировкой «Хайат Тахрир аш-Шам» (запрещена в РФ),

126 Послание Президента РФ Федеральному Собранию от 20.02.2019. Российская газета, 21.02.2019, 38.

${ }^{127}$ Военная доктрина Российской Федерации: утв. Президентом РФ от 25.12.2014 № Пр-2976. Российская газета, 30.12.2014, 298.

${ }^{128}$ Россия и Турция заключили контракт на поставку второго полка С-400. 2020. Сетевое издание РИА Новости. URL: https://ria.ru/20200823/s400-1576196578.html (дата обращения: 10.04.2021).

${ }^{129}$ PM: военно-технический потенциал России выше, чем у США. 2020. Сетевое издание РИА Новости. URL: https://ria.ru/20150604/1068164303.html (дата обращения: 09.04.2021).

${ }^{130}$ How Russian and American Weapons Would Match Up in a New Cold War. 2015. Website «Popular Mechanics». URL: https:/www.britannica.com/topic/North-Atlantic-Treaty-Organization/NATO-in-the-post-ColdWar-era (accessed: 08 April 2021). 
однако сейчас сужается» ${ }^{131}$. Это, в свою очередь, детерминирует значительное укрепление геополитического положения России на Ближнем Востоке и получении надежного союзника в лице Сирии, которая предоставила России возможность дислокации своих вооруженных сил на авиационной военной базе Хмеймим (на бессрочной основе) и военноморской базе в Тартусе ${ }^{132}$.

Усиливается влияние России на африканском континенте. Так, в 2018 году в Центральноафриканскую республику с российской стороны были направлены вооружение и военные инструкторы по просьбе президента Фостен-Арканжа Туадеры [Чаплыгин, 2018]. В 2018 году Россией заключены соглашения с Зимбабве о возможности дозаправки российских военных кораблей в портах данной африканской страны. Также подписаны договоры, позволяющие вести российским предприятиям добычу полезных ископаемых на территории Зимбабве. Отдельным направлением африканской политики России в настоящее время является Ливия. Уже сегодня наша страна активно поддерживает наиболее влиятельного ливийского политика - генерала Хафтара, и в период гражданской войны в Ливии Россия обеспечивала поддержку Ливийской национальной армии путем предоставления специалистов, военной техники, вооружения ${ }^{133}$.

Точкой соприкосновения России и США и их союзников, требующей от первой формировать «ответы» на «вызовы» последнего, является Ледовитый океан и Арктика. Россия продолжает развивать программы по освоению Арктического пространства посредством улучшения имеющихся атомных ледоколов, занимается разработкой новых способов по добыче полезных ископаемых в трудных условиях Севера и приоритетно развивать военную базу «Арктический Трилистник» с параллельным наращиванием строительства новых опорных пунктов в данном регионе [Делягин, 2015]. Помимо этого, в октябре 2020 г. была утверждена «Стратегия развития Арктической зоны Российской Федерации и обеспечения национальной безопасности на период до 2035 года» ${ }^{134}$, где признается, что Арктика является зоной роста конфликтного потенциала, где в настоящее время располагаются объекты стратегических сил сдерживания в целях недопущения агрессии против Российской Федерации и ее союзников.

Стоит отметить, что еще до возникновения «вызова» со стороны стран Запада, необходимость развивать собственную экономику, торговые связи, исследовать внутренние территории для поиска природных ресурсов и патриотическое воспитание молодого поколения назревала достаточно давно в процессе развития России. Решение обозначенных проблем, конечно, осуществлялось, однако «вызовы», выдвигаемые США, стали катализатором, который обострил концентрацию внимания на формировании необходимых «ответов» в связи с сложившимися обстоятельствами. Так, по мнению А. Тойнби, русская цивилизация смогла сохранить свою жизнеспособность благодаря тому, что она отвечала на вызовы внешних условий. На наш взгляд, данная позиция является верной, что подтверждалось историческим развитием и подтверждается современным геополитическим положением Российской Федерации.

Таким образом, из теории «Вызова и Ответа» А.Дж. Тойнби следует, что для становления цивилизации помимо «вызова» важными компонентами являются наличие твор-

131 Лавров заявил об окончании противостояния правительства Сирии и оппозиции. 2020. Сетевое издание РИА Новости. URL: https://ria.ru/20200921/siriya-1577570771.html (дата обращения: 13.03.2021).

${ }^{132}$ Судьба авиабазы Хмеймим и базы ВМФ в Тартусе. 2019. Сетевое издание «Военное обозрение». URL: https://topwar.ru/162989-kakova-sudba-aviabazy-hmejmim-i-bazy-vmf-tartus.html (дата обращения: 08.04.2021)

${ }^{133}$ Путин ввел войска в Ливию. Сможет ли Кремль нанести «удар беженцами» по Европе. 2018. Сайт «Dsnews». URL: http://www.dsnews.ua/world/putin-vvel-voyska-v-liviyu-smozhet-li-kreml-nanesti-udar09102018201500 (дата обращения: 08.01.2021).

${ }^{134}$ О Стратегии развития Арктической зоны Российской Федерации и обеспечения национальной безопасности на период до 2035 года: Указ Президента РФ от 26.10.2020 № 645. Собр. законодательства РФ, 02.11.2020, № 44, ст. 6970. 
ческого порыва меньшинства и готовности общества последовать за этим меньшинством и его порывом, что в совокупности приводит к формированию адекватного «ответа», который консолидирует общество, делая его суверенным от внешнего природного и социального окружения. Так происходит процесс выработки новых способов выживания, что по своей сущности является развитием. Положения, сформулированные А.Дж. Тойнби, находят свое отражение в настоящей действительности. Перед Россией стоит множество «вызовов», наиболее актуальными являются внешнеполитические, которые детерминированы геополитическими амбициями стран Запада во главе с США. «Ответы», которые Российская Федерация пытается дать на возникающие «вызовы», на наш взгляд, являются адекватными, верными и достаточными, укладываемыми в закон британского профессора, являющиеся залогом дальнейшего существования Русской цивилизации.

\section{Список литературы}

1. Блиндер Е. 2020. США поддерживают террористов в Сирии, чтобы сохранить доступ к нефтересурсам. Сетевое издание USA. URL: https://yandex.ru/turbo/usa.one/s/2020/05/sshapodderzhivayut-terroristov-v-sirii-chtoby-soxranit-dostup-k-nefteresursam/ (дата обращения: 06.04.2021).

2. Глазьев С. 2016. Зачем Америке Майдан. Сетевое издание «Аргументы недели». URL: https://argumenti.ru/toptheme/n441/344574 (дата обращения: 02.04.2021).

3. Делягин М.Г. 2015. Арктика становится полигоном для передовых технологий и амбициозных проектов. Сайт «delyagin.ru». URL: https://delyagin.ru/articles/192-deljaginatsitirujut/43196-arktika-stanovitsja-poligonom-dlja-peredovykh-tekhnologi-i-ambitsioznykh-proektov (дата обращения: 25.04.2021).

4. Делягин М.Г. 2016. Они пойдут на Север, если мы не развернем их на Юг. Интернет блок М.Г. Делягина. URL: https://delyagin.ru/articles/187-pozitsija/43379-oni-po-dut-na-sever-esli-myne-razvernem-ikh-na-jug (дата обращения: 02.04.2021).

5. Иванова И.С. 2015. Вопросы современного развития России в условиях новых вызовов. Научные труды Московского гуманитарного университета, 3: 24-29. DOI: 10.17805/trudy.2015.3.3.

6. Тойнби А.Дж. 1991. Постижение истории / пер. с англ.; сост. А.П. Огурцов. М., Прогресс, 736 с.

7. Тойнби А.Дж. 2003. Цивилизация перед судом истории: сб. / пер. с англ. 2-е изд. М., Айрис-пресс, 592 с. $640 \mathrm{c}$.

8. Тойнби А.Дж. 2004. Постижение истории / пер. с англ. Е.Д. Жаркова. М., Айрис-пресс,

9. Чаплыгин А. 2018. Грандиозное возвращение России в Африку. Интернет-проект «ИноСМИ». URL: https://inosmi.ru/politic/20180228/241579862.html (дата обращения: 13.04.2021).

10. Чепиков Е.В. 2013. Методология исследования исторического процесса А. Тойнби. Трансформация цивилизационного учения: монография. Хабаровск, РИО ДВЮИ МВД РФ, 132 с.

11. NATO in the post-Cold War era. 2020. Website «Britannica Group». URL: https://pammtrade.com/strany-nato-kratkaya-istoriya-sozdaniya-alyansa-spisok-stran-nato-5-stadij-rasshireniyaalyansa/12120/ (accessed: 01 February 2021).

\section{References}

1. Blinder E. 2020. SShA podderzhivayut terroristov v Sirii, chtoby sokhranit' dostup k nefteresursam [The United States supports terrorists in Syria to maintain access to oil resources]. Online publication USA. Available at: https://yandex.ru/turbo/usa.one/s/2020/05/ssha-podderzhivayutterroristov-v-sirii-chtoby-soxranit-dostup-k-nefteresursam/ (accessed: 06.04.2021).

2. Glaz'ev S. 2016. Zachem Amerike Maydan [Why America needs Maidan]. Online publication «Argumenty nedeli». Available at: https://argumenti.ru/toptheme/n441/344574 (accessed: 02.04.2021).

3. Delyagin M.G. 2015. Arktika stanovitsya poligonom dlya peredovykh tekhnologiy i ambitsioznykh proektov [The Arctic is becoming a testing ground for advanced technologies and ambitious projects]. Website «delyagin.ru». Available at: https://delyagin.ru/articles/192-deljagina- 
tsitirujut/43196-arktika-stanovitsja-poligonom-dlja-peredovykh-tekhnologi-i-ambitsioznykh-proektov (accessed: 25.04.2021).

4. Delyagin M.G. 2016. Oni poydut na Sever, esli my ne razvernem ikh na Yug [They will go to the North, if we do not turn them to the South]. Internet block of M.G. Delyagin. Available at: https://delyagin.ru/articles/187-pozitsija/43379-oni-po-dut-na-sever-esli-my-ne-razvernem-ikh-na-jug (accessed: 02.04.2021).

5. Ivanova I.S. 2015. Voprosy sovremennogo razvitiya Rossii v usloviyakh novykh vyzovov [Issues of modern development of Russia in the context of new challenges]. Nauchnye trudy Moskovskogo gumanitarnogo universiteta, 3: 24-29. DOI: 10.17805/trudy.2015.3.3.

6. Toynbi A.Dzh. 1991. Postizhenie istorii [Comprehension of history] / trans. from english; comp. A.P. Ogurtsov. Moscow, Publ. Progress, 736 p.

7. Toynbi A.Dzh. 2003. Tsivilizatsiya pered sudom istorii: sb. [Civilization before the court of history: collection] / trans. from english 2nd ed., Moscow, Publ. Ayris-press, 592 p.

8. Toynbi A.Dzh. 2004. Postizhenie istorii [Postizhenie istorii] / trans. from english E.D. Zharkova. Moscow, Publ. Ayris-press, 640 p.

9. Chaplygin A. 2018. Grandioznoe vozvrashchenie Rossii v Afriku [Russia's grand return to Africa]. Internet project «InoSMI». Available at: https://inosmi.ru/politic/20180228/241579862.html (accessed: 13.04.2021).

10. Chepikov E.V. 2013. Metodologiya issledovaniya istoricheskogo protsessa A. Toynbi. Transformatsiya tsivilizatsionnogo ucheniya: monografiya [Methodology of the study of the historical process A. Toynbee. Transformation of civilizational teaching: a monograph]. Khabarovsk, Publ. RIO DVUI of the Ministry of Internal Affairs of the Russian Federation, $132 \mathrm{p}$.

11. NATO in the post-Cold War era. 2020. Website «Britannica Group». URL: https://pammtrade.com/strany-nato-kratkaya-istoriya-sozdaniya-alyansa-spisok-stran-nato-5-stadij-rasshireniyaalyansa/12120/ (accessed: 01 February 2021).

\section{ИНФОРМАЦИЯ ОБ АВТОРЕ}

Вафин Максим Олегович, адъюнкт Дальневосточного юридического института Министерства внутренних дел Российской Федерации, г. Хабаровск, Россия

\section{INFORMATION ABOUT THE AUTHOR}

Maxim O. Vafin, postgraduate student of the Far Eastern Home Ministry Law Institute of the Russian Federation, Khabarovsk, Russia 